\title{
The Research of CDIO-Based Innovative Entrepreneurial Financial Talent Training Mode
}

\author{
Yanling Li, Guojun Sheng, Minghong Sun \\ (Department of Information Management, Dalian Neusoft University \\ of Information, Dalian116023, China,)
}

\begin{abstract}
Keywords: CDIO; Innovation and entrepreneurship; Training mode of talent; University-Enterprise cooperation component
\end{abstract}

\begin{abstract}
Today's China is an unprecedented development of innovation and entrepreneurship. Thus this vigorous economic and political revolution of social innovation and industry upgrading represents the prominent and urgent demands for the innovative and entrepreneurial talents. Based on the research of CDIO initiative, we find that it is strong practical to integrate the innovative and entrepreneurial education into the traditional professional financial students' education. The construction on new training model considers both the horizontal industrial integration and vertical academic research. For the horizontal industrial integration, the aim is to integrate the practical environment into the education resources, such as, SOVO, specialized laboratories, "Ineusoft" ecommerce operation platform, university-enterprise cooperation practice base, etc. Thus, it realizes the combination of the theory and practice as well as the coordinated development of crossfunctionally. The vertical academic research, on one hand, is to optimize four-year financial management courses system insisted on the modern industrial demands. On the other hand, knowledge base and financial consulting company are set up according to the academic financial research, which includes courses, research topics, programs, business activities and innovative and entrepreneurial practice. In this paper, we construct and implement this new financial talent training model based on CDIO system. document.
\end{abstract}

\section{Introduction}

Financial management is generally regarded as an interdisciplinary subject, and highly integrating the theory with practice. Under this new situation, universities are facing great challenges of how to build financial management talent training mode to enhance the students' professional knowledge, abilities and how to cultivate the professional financial management personnel to satisfy the industry and social needs. Nowadays, many limitations exists in the financial management education system, for instance, vagueness in colleges cultivation objectives, lags between the curriculum system and the quick changes of the reality, obsolete teaching methods and tools, weakly practical process, the dislocation of evaluation system etc., which gives rise to more and more substandard graduates who have the poor practical ability and unsolid financial management foundation. However, after years of in-depth research and practice, based on the international advanced education concepts of CDIO engineering initiative, our university established the our own innovation and entrepreneurship financial management talent training mode, aiming to cultivate the talents who will well adapt to the modern social development.

\section{Integrated Innovation and Entrepreneurship into the CDIO-BASED FINANCIAL TALENT TRAINING MODE}

CDIO initiative is one of the most famous international engineering education reform in recent years. Since 2000, with the sponsor of the Knut and Alice Wallenberg foundation (nearly 20 million yuan), the Massachusetts institute of technology and the Swedish royal Institute of technology etc., four 
universities constituted a transnational institute. After four years of research, the institute created CDIO initiative and established the international collaborative committee named after CDIO. CDIO initiative represents Conceive - Design - Implement - Operate complex value-added engineering systems. It is highly summarized and expressed the concept of 'learning by doing' and 'project based education and learning'. It also embodies the basic abilities that modern engineers should have mastered to conduct the modern working process from conception, design to implementation [1]. These abilities includes not only professional technique, but also personal and interpersonal abilities, such as communication ability and creativity in the process[2]. Furthermore, CDIO initiative specifically puts forward the systematic ability training scheme, implementation guidance, as well as implementation process and the evaluation standard of article 12, which makes the education reform have strong maneuverability.

In 2008, after absorbed this advanced CDIO initiative, our school amendment CDIO initiative to our Neusoft TOPCARES - CDIO initiative system considered with the Chinese educational reality and the social demand for financial management personnel. TOPCARES - CDIO initiative system is defined as Technical knowledge and reasoning, Open thinking and innovation, Personal and professional skills, Communication and teamwork, Attitudes and manner, Responsibility, Ethical values, Social contribution by application practice, eight indicators in total. Besides, TOPCARES CDIO eight primary indicators are further subdivided into 32 secondary indicators and 110 tertiary indicators. Under the each tertiary indicator, special quartus indicators are set according to the different requirements of the different majors, to provide the best cultivation and education for the students[3].

\section{The Establishment of the CDIO-BASED INNOVATIVE ENTREPRENEURIAL FINANCIAL TALENT TRAINING MODE}

After having a thorough study of CDIO initiative, our financial management faculty in Dalian Neusoft University of information established our own talent training system, which is the innovative entrepreneurial financial management talent training model based on the TOPCARES-CDIO initiative. We fuse the innovation entrepreneurship gene and invite the enterprise specialists together to construct our training system. After lots of trail and error, enterprise's demand is extracted and subdivided into each training process of the Conceive - Design -Implement - Operating system. CDIO initiative is mapped to our curriculum system [5], for each specific course, topic, project and innovative practical activity. We have built the progressive talent training model for students' fouryear innovation entrepreneurship education, which is horizontally integrated with the industrial practical training resources both inside and outside campus, synchronously, combined with the vertical production-teaching-academic researching triple helix interacted talent training.

Establish The Clear Financial Management Talent Training Target And Our Special Training Feature. Financial management training orientation is, mainly to train practical and informatizational talents. We cultivate the student who not only should have the solid foundation on the financial knowledge and master the financial management basic concept, method and instruments, but also can make the plan of the corporate finance, investment decision and provide financial informatizational service, etc. In order to realize our talent training target, progressive and pluralistic training curriculum is designed to experience the real working environment, like, case study in normal theory course - enterprise simulation project in the practice semester - authentic training in enterprise operation - internship in the collaborative corporate. As an informatizational age, the application of the outstanding enterprise financial softwares (such as SAP, Yongyou etc.) is trained to make the students quickly adjust themselves to the real working position after graduation.

Horizontally Integrated The Industrial Practical Training Resources And Environment Both Inside And Outside School. Education should be combined with social productive labor and social practice, which is the only way to realize human development[4]. So the Academic education 
must keep good communication and interaction with the industry and society in order to cultivate students to conform to the society and the industry development needs. It is known that the production problems result in the research topic, the academic achievements on the contrary will be applied to the actual production. During the construction of financial management training system, a large number of enterprises elements are directly involved in our training model, which is horizontally integrated the industrial practical training resources and environments both inside and outside campus synchronously. SOVO (student office \& venture office), specialized laboratory, and student-managed "INeusoft" real e-commerce operating platform (cross-faculty collaborative practical platform), practical base, Neusoft Group's real corporate program, and flexible learning system MOOCs, are taken as an examples for university-enterprise jointly to improve the construction of the financial management talent training mode.

Vertically Establish The Production-Study-Research Triple Helix Interacted Talent Training System. Our talent training model is built as triple helix interaction system. It vertically combined the academic teaching and research with the modern latest industrial production. Thus the teaching will assist in the research, and moreover, academic achievements can applied to the industrial production, which finally forms a unique practical production-teaching-researching progressive talent training model. To specific, we establish close relationships with enterprises and invite the skilled experts with entrepreneurial, industrial and academic background to exchange the ideas with students. Besides, successful entrepreneurs and VC, PE investors are also welcomed to make the speech and participate in BBS. Teachers are encouraged to be assigned to cooperate with the enterprise for a while, to also cultivate teachers' awareness of entrepreneurship. It assists the scientific and technological achievements to be transferred to the market and helps the entrepreneurship incubation.

Establish The Innovative Entrepreneurial Financial Talent Training Mode Based On TOPCARES-CDIO Initiative. Based on target of the innovative entrepreneurial talent training, the decomposition of the revision of the TOPCARES - CDIO indicators is mapped to the curriculum system[6], specific course, project, and innovation practices. It is to cultivate all the teachers and students of entrepreneurship and innovation ability in the new information age, and to form a strong innovative entrepreneurial culture atmosphere to guide students' behavior. The financial talent training model is horizontally integrated with the industrial practical training resources both inside and outside campus, synchronously connected with the vertical production-teaching-research triple helix interacted system throughout the four-year innovation entrepreneurship cultivation. The curriculum is respectively set as the general innovation entrepreneurship education, special innovation entrepreneurship education and innovation entrepreneurship practice, which aims to train the students' ability of creative thinking, the spirit of innovation entrepreneurship, practical ability and makes the campus as the incubator of innovative entrepreneurs. The framework of TOPCARESCDIO based innovation entrepreneurship financial management talent training mode is shown in the figure below. It is an open, dynamic system for the whole industry and society. The cultivation of students' comprehensive ability, needs to be tested in the enterprise practice and get feedback, to contimuously improve and adjust. Specific Settings as shown. 


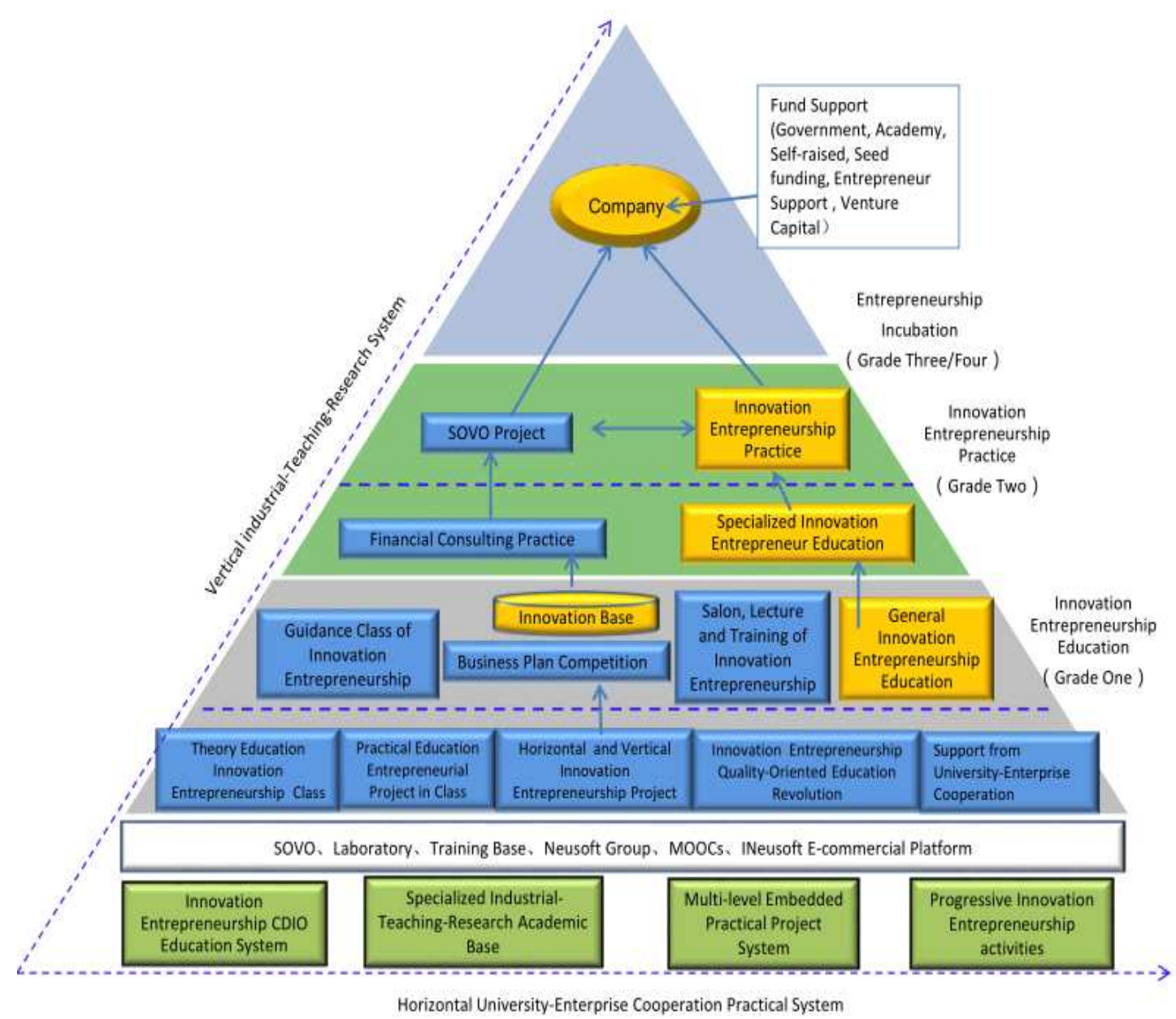

Figure 1. TOPACRES-CDIO-based innovative entrepreneurial financial talent training mode

\section{The Implementation of Innovation and Entrepreneurship Talent Training Mode of Financial Management Based on TOPCARES-CDIO}

The teaching reform of professional financial management is closely based on the TOPCARESCDIO innovation and entrepreneurship training mode, to combine with the financial management professional characteristics and the spirit of Financial management professional Co-Construction Committee, to push forward the reform of professional construction, to decompose the ability index, to put innovation and entrepreneurship education into TOPCARES-CDIO integrated curriculum system, to set up the practice project system of multi layer embedded system, and to develop innovation and entrepreneurship practice[7].

In the aspect of curriculum setting, Financial professional management adhere to the dynamic concept--- " course-need design, and course-post fusion ", according to the policy change, the demand of regional economy and needs of enterprises and professional and personal career development needs, Financial professional management should design courses based on the practical needs, and combine courses with the development of industry.

In the curriculum integration design, the idea, design, implementation, operation (CDIO) project of financial management major, as an important part of TOPCARES-CDIO teaching plan, is divided into five levels: The first level project is financial management professional guidance project (Professional orientation and career planning guidance), financial management professional comprehensive training (through the SAP R / 3 system platform, students experience financial management, cost control business process on the basis of the analysis of real financial data of 
enterprises) and graduation program (graduation thesis and graduation answer). The second level project mainly includes the enterprise operation management, work document design and application practice, enterprise financial management simulation practice, enterprise accounting simulation practice, the application of statistical analysis software and the practice of securities trading, covering the professional skills and professional quality of financial practitioners[8]. Project oriented curriculum ability of fishbone diagram as shown below:

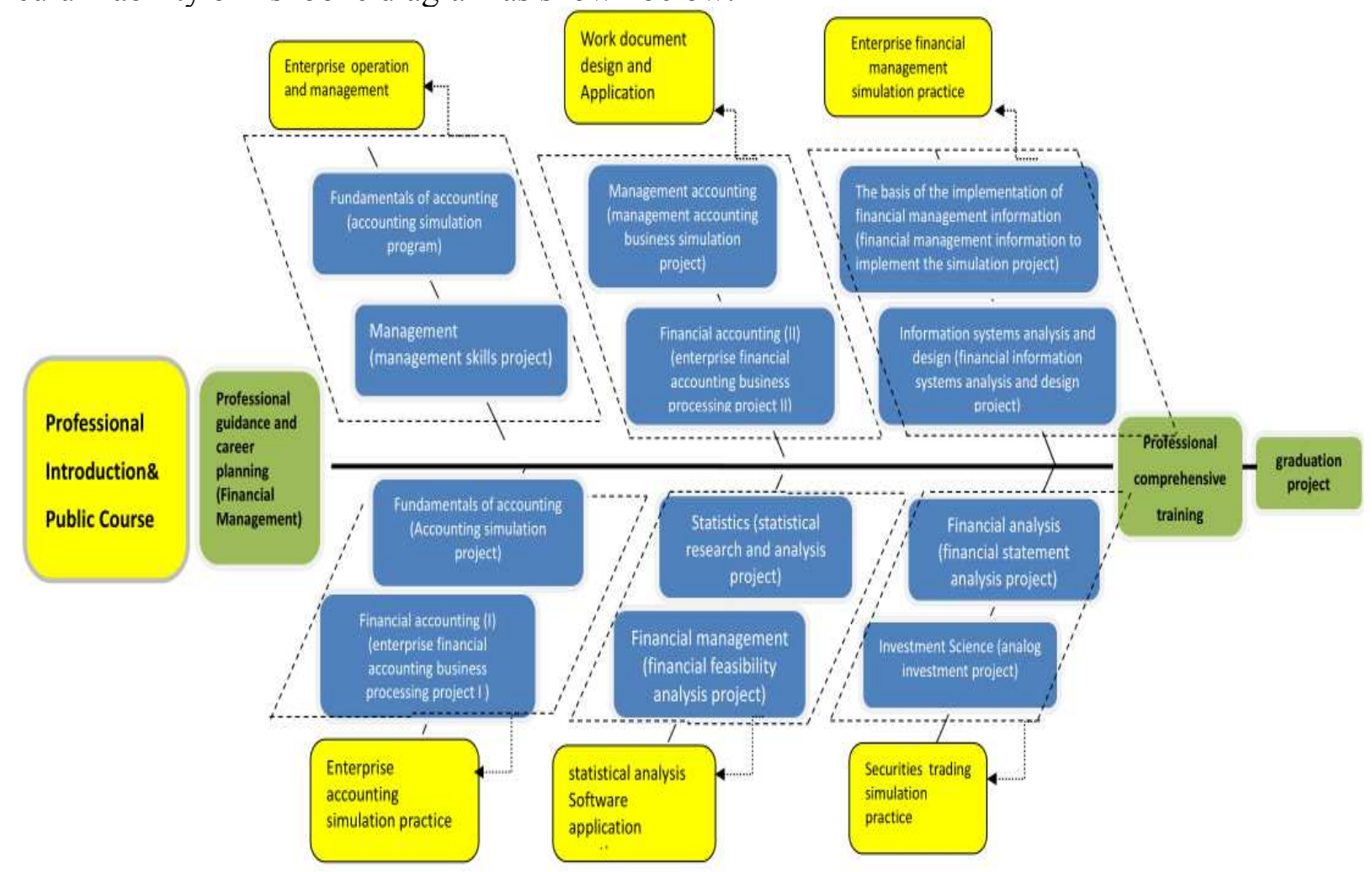

Figure 2. Fishbone diagram for the project oriented curriculum ability

\section{Evaluation}

According to the construction and implementation of the above financial management professional talent training model, the result of the education output is to cultivate talents who meet the needs of industry and society. However, it is also an important issue of concern on the teaching effect and training model test. The major of financial management is to reform the way of student assessment, establish a multi angle quality management and security system, to monitor the quality of teaching and the effect of training[9]. For example, Reform of Students' Evaluation Methods; draw lessons from ABET, CMM, ISO and other quality management concepts and methods, and establish the teaching quality management and security system based on TOPCARES-CDIO talent training mode.

In addition, Innovation and Entrepreneurship College dose numbers of visits and investigation of graduate employers. Innovation and Entrepreneurship College entrust third-party education management data consulting and education quality assessment agencies to track, evaluate and feedback the training quality of professional financial management, and to improve the teaching and training programs dynamically.

\section{Conclusion}

In conclusion, the progressive innovation and Entrepreneurship education is melts into the university four years teaching. Under the background of the integration of production and learning, professional 
financial management is characterized by cultivating practical and informational talents and using the TOPCARES-CDIO model as the basic framework to strengthen students' practical ability, team spirit and cooperation ability, innovative spirit and entrepreneurial courage. Scientific courses, projects, innovation and entrepreneurship practice setting and reasonable quality evaluation are the carrier of the ability to train. Professional knowledge module, ability promotion module and on/off campus module are the main ways to implement personnel training[10]. Through the unremitting efforts and practical exploration and practice, professional financial management will be able to cultivate students to become complex, innovative, international, outstanding practical ability and high quality comprehensive financial management professionals.

\section{Acknowledgment}

Thanks to the Project Number W2014383,the General Project of Education Humanities and Social Sciences in Liaoning Provincial Department of Education " Enterprise Financial Crisis Early Warning Research Based on the Intelligent Multi-Classification Method"

\section{References}

[1] E.F.Crawley. Creating the CDIO Syllabus, a universal template for engineering education, fie, vol.3,Pp.F3F8 -13, 32nd Annual Frontiers in Education(FIE'02) ,2002.

[2] Massachusetts Institute of Technology School of Engineering Committee on Engineering Committee on University undergraduate Education, Eight Goals of an Undergraduate Education, Cambridge, MA,1998.

[3] Wen Tao.The research and practice of talent training model based on TOPCARES-CDIO initiative[J]. Computer Education, 2010,6, 23-29

[4] Pan, M.Y. The New Higher Education [M]. Beijing: Beijing Normal University press, 2009, 2027.

[5] Jiang Xiaoluo,Li Han.CDIO-based Embedded Systems Training Mode in Graduate Teaching,2011 5th International Conference on Distance Learning and Education,2011,73-77.

[6] Li Weicheng. CDIO model of educational philosophy and its practical research [D].Sichuan Normal University,2012.

[7] SUN Cheng-fei.Study on the Optimization of Financial Management Practice Teaching System from the Perspective of Capability Enhancement [J]. Journal of Jianghan University (Social Science Edition), 2015 (06) .

[8] Meng Fanjian. CDIO-based teaching case design [D]. Shijiazhuang Railway University,2013.

[9] Zhang Ying.Based on CDIO concept of China's mechanical design and manufacturing and automation of undergraduate curriculum system research [D]. Zhejiang University, 2014.

[10] Lianzhong Zhang,Li Wang.Research on CDIO engineering education pattern microelectronics technology-driven Teaching Method[A].2013. 